\title{
Mononeuritis Multiplex Associated With Antiphospholipid Antibodies
}

\author{
Luis Francisco VALDÉS CORONA@, Alejandro DÍAZ BORJÓN (D \\ Hospital Angeles Lomas, Rheumatology, Huixquilucan, Mexico
}

\begin{abstract}
In this article, we report the case of a 43-year-old male patient with mononeuritis multiplex associated with antiphospholipid antibodies. The patient had no other clinical or laboratory features of other systemic or autoimmune diseases or systemic vasculitis. He was treated with oral anticoagulant and mycophenolate mofetil, and is progressing favorably.

Keywords: Antibodies, antiphospholipid, mononeuritis multiplex.
\end{abstract}

Mononeuritis multiplex is characterized by multiple isolated neural injuries. Typically, these injuries result from ischemia, traumatic injury, compression, or connective tissue disease. Peripheral nervous system involvement is rarely found in antiphospholipid antibody syndrome (APS), and the association with asymmetric distal axonal polineuropathy is even rarer; the latter is more frequently found in systemic lupus erythematosus and in certain types of vasculitis as polyarteritis nodosa or vasculitis associated with anti-neutrophil cytoplasmic autoantibodies (ANCAs). ${ }^{1-3}$ In this article, we report the case of a patient with mononeuritis multiplex associated with antiphospholipid antibodies. Our objective is to highlight this clinical manifestation associated with the presence of these antibodies, which is actually not considered as part of the classification criteria for APS or even the "extra criteria" manifestations, as well as the serology found and the treatment provided.

\section{CASE REPORT}

A 43-year-old male patient with no significant medical history applied to the clinic for evaluation of a six-week history of paresthesia symptoms in the first, third and fourth fingers of his left hand, with involvement of dorsal region of his right arm, with no apparent trigger. He previously received treatment with vitamin complexes and pregabalin without improvement. A written informed consent was obtained from the patient.

Physical exam was relevant for diminished muscle strength in flexor muscles of the right arm, absent tendon reflexes at right biceps and brachioradialis as well as sensory loss in both hands. Distal pulses were present with normal capillary refill time. There was no livedo reticularis or Raynaud's phenomenon and the rest of physical exam was normal.

Initial general laboratory tests were normal. Thyroid function tests, viral hepatitis serology

Received: May 09, 2019 Accepted: May 30, 2019 Published online: November 06, 2019

Correspondence: Luis Francisco Valdés Corona, MD. Hospital Angeles Lomas, Rheumatology, 52787 Huixquilucan, Mexico. Tel: 52469584 e-mail: luis_v14@hotmail.com 
Table 1. Laboratory and other tests

Complete blood count

Blood chemistry

Urinalysis

Inflammatory markers

Immunologic

Nerve conduction velocity

Tests compatible with antiphospholipid antibody syndrome
Hemoglobin $17 \mathrm{~g} / \mathrm{dL}$, Hematocrit 51\%, White Blood Cells 4,400, Neutrophils 53\%, Lymphocytes $30 \%$, Monocytes 13\%, Band Cells 1\%, Platelets 265,000.

Glucose $83 \mathrm{mg} / \mathrm{dL}$, Creatinine $0.84 \mathrm{mg} / \mathrm{dL}$.

pH 7, Density 1.006, White Blood Cells (-), Proteins (-), Erythrocytes (-).

ESR $3 \mathrm{~mm} / \mathrm{h}$, C-reactive protein $0.020 \mathrm{mg} / \mathrm{dL}$

Rheumatoid factor $11 \mathrm{IU} / \mathrm{mL}$ (negative), ANA and specific ANCA-negative, complement levels within normal limits.

Compatible with mononeuritis multiplex with left median nerve injury and right musculocutaneous nerve injury.

PT-14.6" (14"), PTT-46.5" (28.3”), INR-1.044.

Positive lupus anticoagulant with a PTT LA-61" (0-40") with positive phase confirmation.

Anti-phosphatidylserine Antibodies: IgG-42 U/mL ( $<20 \mathrm{U} / \mathrm{mL})$ and IgM-29 U/mL ( $<25 \mathrm{U} / \mathrm{mL})$

ESR: Erythrocyte sedimentation rate; ANA: Antinuclear antibody; ANCA: Anti-neutrophil cytoplasmic antibody; PT: Prothrombin time; PTT: Partial thromboplastin time; INR: International normalized ratio; LA: Lupus anticoagulant; Ig: Immunoglobulin.

and human immunodeficiency virus serology were negative. A thoracoabdominal angiotomography was performed and resulted negative for vascular anomalies. Magnetic resonance imaging of the spine and brain was normal. Nerve conduction velocities were compatible with mononeuritis multiplex with left median nerve injury and right musculocutaneous nerve injury.

Cerebrospinal fluid analysis was normal and antiganglioside antibodies were within normal limits. Antinuclear antibodies and specific ANCAs were negative, and complement levels were within normal limits. Coagulation tests showed a prolonged activated partial thromboplastin time (PTT). Lupus anticoagulant (LA) was positive, with PTT LA screen positive and a positive hexagonal phase confirmation. Anti-phosphatidylserine antibodies were positive for immunoglobulin (Ig) G and IgM; anti-beta 2-glycoprotein I (antiB2GPI) and anticardiolipin antibodies were within normal limits. Table 1 shows the summary of the tests performed.

The initial treatment was performed with highdose steroids, which was subsequently tapered to suspend. We decided to add mycophenolate mofetil (MMF) as well as anticoagulation therapy with low molecular weight heparin, and subsequently with warfarin; patient has also received physical therapy with an excellent response. He was actually treated with oral anticoagulant and MMF, and is progressing favorably.

\section{DISCUSSION}

Antiphospholipid antibody syndrome is a prothrombotic disease mediated by immunologic phenomena that may affect venous or arterial circulation of any organ or tissue. Neurological manifestations have been classified as thrombotic (e.g. ischemic stroke, transient ischemic attack) and non-thrombotic (e.g. cognitive dysfunction, migraine, myelitis, seizure, chorea, leukoencephalopathy, Guillain-Barré syndrome, multiple sclerosislike syndrome). ${ }^{4,5}$ Besidesischemic stroke, myelitis and some of the non-thrombotic features, other neurologic manifestations are rare, mainly thus related to the peripheral nervous system; nevertheless, they may involve a greater morbidity if diagnosis and treatment are not performed in a timely manner. Mononeuritis multiplex development has been rarely associated with antiphospholipid antibodies; as far as we know, there are only three cases reported. This has not been clearly associated with diagnosis of APS, but with positive serology. Pathophysiology of this manifestation may be caused by autoantibodies, immune complex deposition or direct injury caused by vasculitis or thrombosis of the vasa nervorum. The mechanisms by which these antibodies might induce a procoagulant state have not been fully elucidated, but clot formation could be the result of the interaction of the antibodies with endothelial cells, neutrophils, platelets and monocytes. ${ }^{4}$ Interestingly, suffering from mononeuritis multiplex at the time of the 
diagnosis predicts the need of immunosuppressive therapy in patients with vasculitis without poorprognosis factors. ${ }^{6-9}$ It is relevant that mononeuritis multiplex is not recognized as an extra criteria manifestation of APS, ${ }^{4}$ but this could represent a no traditional clinical feature.

Apart from conventional biological markers for APS (LA, anticardiolipin antibodies and anti-B2GPI of either IgG or IgM), numerous other markers of APS have been studied. These antibodies are known as non-conventional and include the anti phosphatidyl-ethanolamine, phosphatidylserine/ prothrombin, anti-vimentin, anti-annexin, and antibodies directed against domain I of the B2GPI molecule. Particularly, anti-phosphatidylserine antibodies have been related as a strong risk factor for arterial and venous thrombosis and have a very strong correlation with LA positivity as it occurred in this case. ${ }^{10,11}$

Regarding the treatment, corticosteroids and other immunosuppressant therapies have been reported in some studies to decrease titers of LA and anticardiolipin antibodies. ${ }^{12}$ Even though immunosuppressive treatment is not indicated in the management of APS except in the presence of catastrophic APS, there is no consensus or formal recommendation in the treatment of these type of affections; thus the rationale for administering immunosuppressive therapy used in this case was solely based on expert opinion.

\section{Declaration of conflicting interests}

The authors declared no conflicts of interest with respect to the authorship and/or publication of this article.

\section{Funding}

The authors received no financial support for the research and/or authorship of this article.

\section{REFERENCES}

1. Giannakopoulos B, Krilis SA. The pathogenesis of the antiphospholipid syndrome. $\mathrm{N}$ Engl $\mathrm{J}$ Med 2013;368:1033-44.
2. Miyakis S, Lockshin MD, Atsumi T, Branch DW, Brey RL, Cervera R, et al. International consensus statement on an update of the classification criteria for definite antiphospholipid syndrome (APS). J Thromb Haemost 2006;4:295-306.

3. Kafka SP, Condemi JJ, Marsh DO, Leddy JP. Mononeuritis multiplex and vasculitis. Association with anti-neutrophil cytoplasmic autoantibody. Arch Neurol 1994;51:565-8.

4. Sciascia S, Amigo MC, Roccatello D, Khamashta M. Diagnosing antiphospholipid syndrome: 'extracriteria' manifestations and technical advances. Nat Rev Rheumatol 2017;13:548-560.

5. Ricarte IF, Dutra LA, Abrantes FF, Toso FF, Barsottini OGP, Silva GS, et al. Neurologic manifestations of antiphospholipid syndrome. Lupus 2018;27:1404-14.

6. Jeruc J, Popovic M, Vizjak A, Jurcic V, Lestan B, Ferluga D. Multiple mononeuropathy due to vasculitis associated with anticardiolipin antibodies: a case report. Folia Neuropathol 2006;44:140-3.

7. Rodrigues CE, Carvalho JF. Multiple mononeuropathy secondary to thrombosis of the vasa nervorum in primary antiphospholipid syndrome. Isr Med Assoc $\mathrm{J}$ 2010;12:448-9.

8. Erten N, Saka B, Karan MA, Parman Y, Umman B, Tascioglu C. Catastrophic secondary antiphospholipid syndrome with peripheral nervous system involvement: a case report. Acta Med Okayama 2004;58:107-10.

9. Samson M, Puéchal X, Devilliers H, Ribi C, Cohen P, Bienvenu B, et al. Mononeuritis multiplex predicts the need for immunosuppressive or immunomodulatory drugs for EGPA, PAN and MPA patients without poor-prognosis factors. Autoimmun Rev 2014;13:945-53.

10. Zigon P, Podovsounik A, Ambrozic A, Tomsic M, Hocevar A, Gaspersic N, et al. Added value of non-criteria antiphospholipid antibodies for antiphospholipid syndrome: lessons learned from year-long routine measurements. Clin Rheumatol 2019;38:371-8.

11. Núñez-Álvarez CA, Hernández-Molina G, BermúdezBermejo P, Zamora-Legoff V, Hernández-Ramírez DF, Olivares-Martínez E, et al. Prevalence and associations of anti-phosphatidylserine/prothrombin antibodies with clinical phenotypes in patients with primary antiphospholipid syndrome: aPS/PT antibodies in primary antiphospholipid syndrome. Thromb Res 2019;174:141-7.

12. Keswani SC, Chauhan N. Antiphospholipid syndrome. J R Soc Med 2002;95:336-42. 